\title{
3 Research Square \\ Sex Difference in The Association Between Plasma Selenium and First Stroke: A Community-Based Nested Case-Control Study
}

Huan Hu

the second affiliated hospital of nanchang university https://orcid.org/0000-0002-1685-9755

Chonglei Bi

Peoples' Hospital of Rongcheng

Tengfei Lin

China Agricultural University

Lishun Liu

China Agricultural University

Yun Song

China Agricultural University

Binyan Wang

Anhui Medical University

Ping Wang

Sun Yat-Sen University

Ziyi Zhou

China Agricultural University

Chongqian Fang

People's Hospital of Rongcheng

Hai Ma

Health and Family Commission of Rongcheng

Xiao Huang

the second affiliated hospital of nanchang university

Lihua $\mathrm{Hu}$

the second affiliated hospital of nanchang university

Xiping Xu

China Agricultural University

Hao Zhang

China Agricultural University

Yong Huo

Peking University First Hospital

Xiaobin Wang 
Johns Hopkins University

\section{Huihui Bao}

The second affiliated hospital of nanchang university

\section{Xiaoshu Cheng}

the second affiliated hospital of nanchang university

\section{Ping Li ( $\mathbf{1 8 3 4 2 0 7 5 5 @ q q . c o m ) ~}$}

The Second Affiliated Hospital of Nanchang University https://orcid.org/0000-0003-3112-0139

\section{Research}

Keywords: Selenium, First stroke, First ischemic stroke, First hemorrhagic stroke, Vitamin E Posted Date: January 11th, 2021

DOl: https://doi.org/10.21203/rs.3.rs-141452/v1

License: (c) (1) This work is licensed under a Creative Commons Attribution 4.0 International License. Read Full License 


\section{Abstract}

Background: To date, there is no clearly defined association between plasma selenium levels and first stroke. We aimed to investigate the association between baseline plasma selenium and first stroke risk in a community-based, Chinese population.

Methods: Using a nested case-control study design, a total of 1255 first stroke cases and 1255 matched controls were analyzed. Participant plasma selenium concentrations were measured by inductively coupled plasma mass spectrometry (ICP-MS) and the association of plasma selenium with first stroke risk was estimated by conditional logistic regression models.

Results: Overall, a nonlinear negative association between plasma selenium with first total stroke and first ischemic stroke risks was found in males, but not in females. Compared with participants with lower selenium levels (tertile $1-2,<94.1 \mathrm{ng} / \mathrm{mL}$ ), participants with higher selenium levels (tertile $3, \geq 94.1 \mathrm{ng} / \mathrm{mL}$ ) had significantly lower risks of first total stroke (OR: $0.63 ; 95 \% \mathrm{Cl}: 0.48,0.83)$ and first ischemic stroke (OR: $0.61 ; 95 \% \mathrm{Cl}: 0.45,0.83)$ in males, but not in females with first total stroke (OR: $0.92 ; 95 \% \mathrm{Cl}: 0.69$, 1.22 ) and first ischemic stroke (OR: $0.89 ; 95 \% \mathrm{Cl}: 0.65,1.22)$. Furthermore, a stronger association between plasma selenium and first total stroke was found in males with higher vitamin E levels $(\geq 13.5 \mu \mathrm{g} / \mathrm{mL} v s$. $<13.5 \mu \mathrm{g} / \mathrm{mL} P$-interaction=0.007). No significant association was observed between plasma selenium and first hemorrhagic stroke risk in either males or females.

Conclusion: Our study indicated a significant, nonlinear, negative association between plasma selenium and first stroke in males, but not in females.

TRIAL REGISTRATION: ChiCTR1800017274.

\section{Introduction}

Stroke is a leading cause of mortality and disability worldwide. Accounting for almost one third of worldwide stroke mortality, China bears the heaviest stroke burden in the world [1,2]. Since control of risk factors for stroke helps decrease stroke burden [3,4], the identification of novel risk factors is urgent to further lower stroke risk. Recently, accumulating evidence has indicated that trace elements might exert effects on stroke $[5,6]$.

Selenium (Se), an essential trace element, acts as the active center of selenoproteins or selenoenzymes (eg, glutathione peroxidases), which have many important biological functions including antioxidant, anti-inflammatory and immunoregulatory roles [7-9]. Insufficient or excessive selenium intake may be associated with many adverse health outcomes [10-12]. Particularly, health problems caused by selenium deficiency need to be given great attention in China, a Se-deficient country where it is estimated that over 105 million people potentially face adverse health impacts due to selenium deficiency $[13,14]$. Although cross-sectional epidemiologic studies have indicated inverse associations between selenium levels with stroke risk [15-17], previous prospective epidemiologic studies have reported inconsistent findings on the 
associations between selenium concentrations with stroke risk [18-21]. Moreover, few studies have thoroughly analyzed the potential modifiers affecting this association. Therefore, the prospective relationship between plasma selenium and risk of first stroke remains inconclusive and deserves further investigation.

To fill the knowledge gap mentioned above, we performed a nested case-control study to investigate the association between baseline plasma selenium levels and risk of first total stroke and stroke subtypes (ischemic stroke and hemorrhagic strokes), and examined any possible effect modifiers using data from a community-based population in China. To the best of our knowledge, this study is the first of its kind to evaluate this relationship in a community-based Chinese population.

\section{Methods}

\section{Study population and design}

Our present study is a subset of the China H-type Hypertension Registry Study (CHHRS; URL:

http://www.chictr.org.cn; Unique identifier: ChiCTR1800017274) which was an ongoing community-based non-intervention, prospective, observational, multicenter, real-world registry study and was mainly conducted in Rongcheng county, Shandong province, and Lianyungang, Jiangsu province, China. It was designed to establish a national registry of patients with hypertension, to investigate the prevalence and treatment of $\mathrm{H}$-type hypertension in China and the related factors affecting its prognosis, and finally to construct a risk prediction model of cardio-cerebral and renal vascular diseases. Eligible participants were men and women aged $\geq 18$ years with essential hypertension, defined as seated systolic blood pressure $(\mathrm{SBP}) \geq 140 \mathrm{~mm} \mathrm{Hg}$ and/or seated diastolic blood pressure (DBP) $\geq 90 \mathrm{~mm} \mathrm{Hg}$ at the screening visit. Participants were excluded if they had psychological or nervous system impairment resulting in an inability to demonstrate informed consent or were unable to be followed-up according to the study protocol. The trial consisted of 2 stages: screening and recruitment and a 3-year observation follow-up period. Participants were scheduled for follow-up every 3 months. At each visit, blood pressure, heart rate, the usage of medications, adverse events, and study outcome events were measured and recorded. The primary outcome was first composite of cardiovascular events consisting of nonfatal stroke, myocardial infarction, and vascular death and all-cause death.

The current nested case-control study utilized data from the CHHRS which had been conducted in Rongcheng, a coastal area of Shandong province, China. This study matched stroke cases with an equal number of controls (patients without stroke) by age \pm 1 year, sex, and village. Patients with stroke data from the Chinese Centers for Disease Control and Prevention (CDC, 2016-2018) who had complete records (physical exam, questionnaire, and biological samples) were selected as cases. The initial sample consisted of 1401 incident cases and 1401 matched controls. Next, we excluded participants with missing serum calcium value $(n=287)$ and unpaired individuals $(n=5)$. Based on the inclusion and exclusion criteria, 1255 stroke cases and 1255 matched controls with complete calcium measurements were selected for final data analysis (Supplementary Figure 1). 


\section{Ethics}

The present study was approved by the Ethics Committee of the Institute of Biomedicine, Anhui Medical University, Hefei, China. All participants signed an approved written consent form after the study protocol was thoroughly explained to them.

\section{Outcomes}

The primary outcome of the present study was a first nonfatal or fatal stroke. Secondary outcomes included first ischemic stroke (fatal and nonfatal), and first hemorrhagic stroke (fatal and nonfatal).

Information on incidence of first stroke for all participants was obtained via the Center for Disease Control and Prevention of Rongcheng county, and checked against the national health insurance system with electronic linkage to all hospitalizations, or ascertained through active follow-up. Diseases were coded according to the International Classification of Diseases, 10th Revision (ICD-10). Secondary outcomes included first ischemic stroke (163) and first hemorrhagic stroke (160-161). The primary outcome (first nonfatal or fatal stroke) included first ischemic stroke (163), first hemorrhagic stroke (160-161) and no type stroke (164).

According to government regulations, local authorities from medical institutions are required to report all new cases of stroke to the local Center for Disease Control and Prevention. A report card which includes information on demographics, diagnostic basis and date of stroke is required to be submitted on the 28th of each month. Quality control, including finding and deleting repeated cases, error checking, and determining any missed cases, is completed by trained officials. Furthermore, the staff from the local Center for Disease Control and Prevention would double check these information and also be responsible for deleting repeated cases and finding logistical errors and missed cases. In addition, $5 \%$ of all uploaded cases are randomly chosen for further confirmation by phone or door-to-door interviews.

\section{Laboratory assays}

Baseline serum total homocysteine (tHcy), fasting glucose levels, and lipids were measured using automatic clinical analyzers (Beckman Coulter, AU680) at the Shenzhen Tailored Medical laboratory in Shenzhen, China. Estimated glomerular filtration rates (eGFR) were estimated by the Chronic Kidney Disease Epidemiology Collaboration equation. Baseline plasma vitamin E concentrations were measured using liquid chromatography-tandem quadrupole mass spectrometry (LC-MS/MS) and plasma selenium concentrations were measured by inductively coupled plasma mass spectrometry (ICP-MS) using Thermo Fisher iCAP Q ICP-MS in a commercial laboratory (Beijing DIAN Medical Laboratory, China). In the present study, the intra-assay CV for selenium ranged from $1.02 \%$ to $7.93 \%$, while the inter-assay CV for selenium ranged from $2.79 \%$ to $3.51 \%$. According to a previous study [22], the reference value $(50-120 \mathrm{ng} / \mathrm{mL})$ for plasma selenium levels was used in this study.

\section{Statistical analysis}


Baseline characteristics are presented as means \pm SDs for continuous variables and as frequency (\%) for categorical variables. Differences in baseline characteristics between males and females, and cases and controls, were compared using Chi-square tests for categorical variables and $t$ tests for continuous variables. Differences in population characteristics according to selenium tertiles were compared using ANOVA tests, or Chi-square tests, accordingly.

Variables that are known as traditional or suspected risk factors for stroke [23], and matched variables or variables that showed significant differences between cases and controls were adjusted for in the models. Odds ratios (ORs) and 95\% confidence intervals ( $95 \% \mathrm{Cls}$ ) for first stroke, first ischemic stroke, and first hemorrhagic stroke were calculated by modeling plasma selenium as tertiles using conditional logistic regression, without and with adjustment for matched variables (sex and age), body mass index (BMI), baseline systolic blood pressure (SBP), baseline diastolic blood pressure (DBP), smoking status, alcohol consumption, labor intensity, baseline total homocysteine (tHcy), plasma vitamin E, fasting glucose, estimated glomerular filtration rate (eGFR), antiplatelet drugs, lipoprotein-lowering drugs, glucose-lowering drugs, antihypertensive drugs, self-reported hypertension, self-reported diabetes, selfreported atrial fibrillation, and self-reported hyperlipidemia. A generalized additive model (GAM) and smooth curve fitting (penalized spline method) were evaluated to further characterize the shape of the association between serum selenium and first stroke and its subtypes. As additional exploratory analyses, possible modifications of the association between plasma selenium (tertile $3, \geq 94.1 \mathrm{vs}$. tertile $1-2,<94.1 \mathrm{ng} / \mathrm{mL}$ ) and first total stroke in male and female participants were also assessed for variables including age ( $<70 v s . \geq 70 \mathrm{y}), \mathrm{BMI}\left(<24 v s . \geq 24 \mathrm{~kg} / \mathrm{m}^{2}\right)$, current smoking (yes $v s$. no), current alcohol drinking (yes vs. no), baseline SBP ( $<140 v s . \geq 140 \mathrm{mmHg}$ ), fasting glucose $(<6.1 \mathrm{vs} . \geq 6.1 \mathrm{mmol} / \mathrm{L}$ or diabetes), total cholesterol $(<5.78$ [median] $v s . \geq 5.78 \mathrm{mmol} / \mathrm{L})$, triglycerides $(<1.17$ [median] $v s . \geq 1.17$ $\mathrm{mmol} / \mathrm{L})$, estimated glomerular filtration rate $\left(<90 \mathrm{vs} . \geq 90 \mathrm{~mL} / \mathrm{min} / 1.73 \mathrm{~m}^{2}\right)$, total homocysteine $(<12.5$ [median] $v s . \geq 12.5 \mu \mathrm{mol} / \mathrm{L})$, and vitamin $\mathrm{E}(<13.5$ [median] $v s . \geq 13.5 \mu \mathrm{mol} / \mathrm{L})$ using multivariate logistic regression models. Diabetes was defined as fasting serum glucose $\geq 7.0 \mathrm{mmol} / \mathrm{L}$ or self-reported use of anti-diabetic medications, or physician diagnosed diabetes. Potential interactions were examined by including the interaction terms into those logistic regression models with the greatest number of confounding variables.

A 2-tailed $P<0.05$ was considered to be statistically significant in all analyses. R software version 3.4.3 (www.R-project.org) and Empower version 2.17.8 (www.empowerstats.com, X\&Y Solutions, Inc.) were used for all statistical analyses.

\section{Results}

\section{Study participants and baseline characteristics}

A total of 1255 first stroke cases (1079 cases of first ischemic stroke, 171 cases of first hemorrhagic stroke, and 5 cases of first uncertain type of stroke) and 1255 matched controls were included in this analysis. The mean age of all participants at baseline was 70.75 years (SD, 8.06), 49.48\% of the 
participants were male and the mean selenium level was $87.24 \mathrm{ng} / \mathrm{mL}(\mathrm{SD}, 18.57)$. Baseline characteristics of male and female participants are shown in Table 1. Detailed plasma selenium concentration distribution of subjects is listed in Supplemental Table 1 and $95.1 \%$ of the participants were within the normal range of selenium levels as the reference value $(50-120 \mathrm{ng} / \mathrm{mL})$ for plasma selenium concentrations. As shown in Table 1, male participants had non-significantly higher selenium levels than females ( $87.68 \pm 18.58 \mathrm{vs} .86 .80 \pm 18.55 \mathrm{ng} / \mathrm{mL} ; P=0.230)$. Males also tended to be older, were more likely to be current smokers and current drinkers, had higher DBP and tHcy levels, as well as lower BMI, SBP, TC, TG, glucose, and vitamin E levels at baseline and a lower frequency of lipid-lowering, glucose-lowering and antihypertensive drug use, and were less likely to be hypertensive patients, or selfreported diabetic and self-reported hyperlipidemia patients compared with female participants.

Baseline characteristics of cases and control participants are shown in Table 2. Stroke cases had nonsignificantly lower selenium levels than controls ( $86.63 \pm 17.63 \mathrm{vs} .87 .84 \pm 19.45 \mathrm{ng} / \mathrm{mL} ; P=0.101)$. Stroke cases also tended to have higher BMI, baseline BP, TG, fasting glucose, tHcy levels, and a higher frequency of antiplatelet, glucose-lowering and antihypertensive drug use, were more likely to be current smokers, hypertensive and self-reported diabetic patients, as well as have lower high-density lipoproteincholesterol levels at baseline compared with controls. In addition, plasma selenium was positively associated with BMI, current smoking, current alcohol drinking, self-reported diabetes, higher frequency of glucose-lowering drug use, TC, high-density lipoprotein-cholesterol, fasting glucose, and vitamin E levels and was inversely associated with labor intensity and tHcy levels at baseline (Supplemental Table 2).

\section{Association between plasma selenium concentration and first stroke in total participants}

Overall, there was a nonlinear negative association between plasma selenium levels with the risk of first total stroke and first ischemic stroke (Fig. 1A and Fig. 1B), but not with the risk of first hemorrhagic stroke (Supplemental Fig. 2A) in total participants. Consistently, when plasma selenium was assessed as tertiles, significantly lower risks of first total stroke (Model 2, OR: $0.77 ; 95 \% \mathrm{Cl}: 0.61,0.97$ ) and first ischemic stroke (Model 2, OR: 0.78; 95\%Cl: 0.60, 0.99) were found in participants in tertile 3 ( $\geq 94.1$ $\mathrm{ng} / \mathrm{mL})$ than in those in tertile $1(<79.1 \mathrm{ng} / \mathrm{mL})$ (Table 3). Due to the similar first total stroke and first ischemic stroke prevalence in participants with selenium levels in tertile 1 and tertile 2 (Table 3 ), we combined these two groups into one group called tertile 1-2. Compared with participants with lower selenium levels in tertile $1-2(<94.1 \mathrm{ng} / \mathrm{mL})$, significantly lower risks of first total stroke (Model 2, OR: 0.76; $95 \% \mathrm{Cl}: 0.63,0.93$ ) and first ishcemic stroke (Model 2, OR: $0.75 ; 95 \% \mathrm{Cl}: 0.61,0.93$ ) were found in those with a higher selenium levels in tertile $3(\geq 94.1 \mathrm{ng} / \mathrm{mL}$ ) (Table 3 ). However, no significant association was found between plasma selenium concentrations and first hemorrhagic stroke (Table 3 ).

\section{Association between plasma selenium concentrations and first stroke by sex}

Given the differences in plasma selenium levels between male and female participants (87.68 $\pm 18.58 \mathrm{vs}$. $86.80 \pm 18.55 \mathrm{ng} / \mathrm{mL}$ ), we further investigated the possible effect of sex on the selenium-first stroke association. Overall, there was a nonlinear negative association between plasma selenium levels with the risks of first total stroke and first ischemic stroke in males (Fig. 1C and Fig. 1D), but not in females (Fig. 
$1 \mathrm{E}$ and Fig. 1F). Furthermore, there was no significant association between plasma selenium and first hemorrhagic stroke in both sexes (Supplemental Fig. 2B-C). Consistently, when plasma selenium was assessed as tertiles, the highest tertile $(T 3, \geq 94.1 \mathrm{ng} / \mathrm{mL})$ of plasma selenium was associated with a lower first total stroke risk in males (Model 2, OR: $0.67 ; 95 \% \mathrm{Cl}: 0.48,0.93, P=0.017$ ), but not in females (Model 2, OR: $0.85 ; 95 \% \mathrm{Cl}: 0.61,1.19, P=0.353)$ compared with the lowest tertile $(T 1,<79.1 \mathrm{ng} / \mathrm{mL}$ ) of plasma selenium (Table 4). Accordingly, higher selenium levels in tertile $3(\geq 94.1 \mathrm{ng} / \mathrm{mL})$ were associated with a lower first total stroke risk in males (Model 2 OR: $0.63 ; 95 \% \mathrm{Cl}: 0.48,0.83, P=0.001$ ), but not in females (Model 2, OR: 0.92; 95\% Cl: 0.69, 1.22, $P=0.563$ ) compared with lower selenium levels in tertile 1-2 (<94.1 ng/mL) (Table 4).

Similar effects of sex on the selenium-first ischemic stroke association were also observed and are displayed in Table 4. However, no significant association was found between plasma selenium and first hemorrhagic stroke risk among both males and females (Table 4).

\section{Stratified analysis by potential effect modifiers in male and female participants}

Stratified analyses were conducted to explore potential modifiers affecting the association between plasma selenium (tertile $3, \geq 94.1 \mathrm{vs}$. tertile $1-2,<94.1 \mathrm{ng} / \mathrm{mL}$ ) and first total stroke risk among male participants (Table 5). A stronger nonlinear negative association between baseline plasma selenium and first total stroke was found among males with higher vitamin E levels compared to those with lower vitamin E levels ( $\geq 13.5 \mu \mathrm{g} / \mathrm{mL}$; OR, 0.39; 95\%Cl: 0.25, 0.60; vs. $<13.5 \mu \mathrm{g} / \mathrm{mL} ; \mathrm{OR}, 0.85 ; 95 \% \mathrm{Cl}: 0.62,1.17 ; P$ for interaction=0.007). None of the other variables, including age ( $<70 v s . \geq 70$ years), BMI ( $<24 v s . \geq 24$ $\mathrm{kg} / \mathrm{m}^{2}$ ), current smoking (yes $v s$. no), current alcohol drinking (yes $v s$. no), baseline SBP (<140 vs. $\geq 140$ $\mathrm{mmHg}$ ), fasting glucose ( $<6.1 \mathrm{vs} . \geq 6.1 \mathrm{mmol} / \mathrm{L}$ or diabetes), TC ( $<5.78$ [median] $v s . \geq 5.78 \mathrm{mmol} / \mathrm{L}), \mathrm{TG}$ ( $<1.17$ [median] vs. $\geq 1.17 \mathrm{mmol} / \mathrm{L})$, eGFR $\left(<90 \mathrm{vs} . \geq 90 \mathrm{~mL} / \mathrm{min} / 1.73 \mathrm{~m}^{2}\right)$, and total homocysteine $(<12.5$ [median] vs. $\geq 12.5 \mu \mathrm{mol} / \mathrm{L}$ ) were found to modify the association between plasma selenium (tertile 3 , $\geq 94.1 \mathrm{vs}$. tertile $1-2,<94.1 \mathrm{ng} / \mathrm{mL}$ ) and the risk of first stroke in males ( $P$ for all interactions $>0.05$ ).

Furthermore, none of the above variables significantly modified the association of plasma selenium and the risk of first total stroke in female participants ( $P$ for all interactions $>0.05$ ) (Supplemental Table 3 ).

\section{Discussion}

This nested case-control study demonstrates that higher baseline plasma selenium is associated with lower risks of first total stroke and first ischemic stroke in males, but not in females. Plasma vitamin $\mathrm{E}$ levels significantly modified the association between plasma selenium and first total stroke in males. Furthermore, no significant association was found between plasma selenium and first hemorrhagic stroke risk in either male or female participants.

Conflicting findings of the association between plasma selenium and the risk of stroke have been reported by previous studies. A nested case-control study [20] enrolling 1304 stroke cases found that higher plasma selenium levels were significantly associated with a lower risk of hemorrhagic stroke, but 
not ischemic stroke; the odds ratios (ORs) of hemorrhagic and ischemic stroke were 0.68 (95\% Cl: 0.51 , $0.91)$ and $0.92(95 \% \mathrm{Cl}: 0.82,1.05)$ in the higher selenium levels in tertile 3 (compared with tertile 1$)$. One case-control study [17] including 1277 ischemic stroke patients indicated that higher plasma selenium levels were associated with a decreased risk of ischemic stroke, where the OR for those with higher selenium levels in quartile 4 (compared with quartile 1 ) was $0.10(95 \% \mathrm{Cl}: 0.06,0.17)$. Moreover, the Canadian Health Measures Survey (CHMS) and the National Health and Nutrition Examination Study (NHANES) found inverse, cross-sectional associations between whole blood selenium and prevalence of stroke, as well as the Inuit Health Survey (IHS) indicated a reverse relation of whole blood and dietary selenium levels with stroke, but revealed an L-shaped relationship [15,16]. However, the Reasons for Geographic and Racial Differences in Stroke Study (REGARDS) [18] revealed that higher environmental selenium levels were associated with increased stroke risk; the hazard ratio (HR) for those with higher selenium levels in quartile 4 (compared with quartile 1) was $1.33(95 \% \mathrm{Cl}: 1.09,1.62)$. It is noteworthy that all of these studies used different sources (plasma, whole blood, diet, and environment) of selenium levels to assess the association between selenium levels and stroke, which might be one reason for the discrepancy of these findings.

Several studies have also explored the association between selenium and stroke mortality, specifically. A cohort study [19] enrolling 23 stroke death cases among 1100 Finnish males found that low serum selenium $(<45 \mu \mathrm{g} / \mathrm{L})$ was associated with a higher risk of stroke mortality, reporting an adjusted relative risk of $3.7(95 \% \mathrm{Cl}: 1.0,13.1)$. The NHANES III cohort study [24] including 13887 participants found that the association curve for selenium and stroke mortality had a reversed U-shape. However, another cohort study including 1103 Chinese participants found no significant association of plasma selenium levels and stroke mortality [25]. Notably, these studies focused on stroke mortality and these findings might not represent the association of plasma selenium levels and first stroke risk. Similarity, prospective associations between selenium status/intake and cardiovascular outcomes remain inconclusive [26-28]. None of the above research reported a sex difference in the association between plasma selenium and stroke risk, and the results of these studies remain inconclusive. The present study provides an opportunity to explore the possible relation of plasma selenium and first stroke, and to examine the potential effect modifiers in a community-based Chinese population.

Our current study provides three new insights into the field. First, to the best of our knowledge, this is the first study to find a significantly nonlinear, inverse association between plasma selenium with first total stroke and first ischemic stroke risks in males, but not in females. The differences in the primary outcome (first stroke) between sex in our study may be explained by the differences in the way selenium is metabolized between the male and female reproductive systems. The retention rate for selenium is highly efficient in the testes, while it appears that the female reproductive system does not retain significant levels of selenium as efficiently [29-31]. In addition, the testes might compete for selenium utilization with the brain under selenium-compromised conditions [32], suggesting that the brain in males might be more susceptible to selenium deficiency than in females. The interaction of selenium with the thyroid axis may be another reason for the differences. Wang et al. [33] has demonstrated strong sex-specific differences in risk and development for hyperthyroidism in relation to baseline selenium intake, selenium deficiency 
might constitute a risk factor for hyperthyroidism in males but no substantial association was found between hyperthyroidism prevalence and selenium status in females. Since hyperthyroidism has been reported to associate with 2- to 3-fold increased risk for ischemic and non-ischemic stroke [34]. Therefore, we speculate that high selenium levels may reduce the adverse effects in males due to the selenium deficiency, which may explain why the nonlinear inverse association between serum selenium and first stroke was mainly found among males. Further prospective studies are needed to verify this differential association by sex.

Second, we observed a sharp decline in the risk of first stroke when plasma selenium was over 94.1 $\mathrm{ng} / \mathrm{mL}$, suggesting that this value might serve as a high plasma selenium cut-off point marking a decreased risk of first stroke or a low plasma selenium cut-off point marking an increased risk of first stroke. This cut-off value agrees with a previous study which reported that plasma selenium $>90 \mu \mathrm{g} / \mathrm{L}$ was sufficient to optimize functions of selenoproteins [35], which are believed to carry out the functions of selenium in the role of selenium compounds. Schomburg Lutz et.al [36] also reported that deficiency of Selenoprotein-P, the main carrier of selenium to target organs and reduces tissue oxidative stress both directly and by delivering selenium to protective selenoproteins, was associated with increased risk of stroke in a North European population without history of cardiovascular disease. However, it should also be noted that this cut-off value is still within the normal range for human plasma selenium (50-120 $\mathrm{ng} / \mathrm{mL}$ ) [22], and our findings were found mainly among a population with normal selenium levels, with a prevalence of plasma selenium $<50,50$ to 120 , and $>120 \mathrm{ng} / \mathrm{mL}$ of $1.2 \%, 95.1 \%$, and $3.7 \%$ in this study (Supplemental Table 1). Therefore, the use of the cut-off value for plasma selenium concentration among stroke patients needs careful consideration. Our results, if further confirmed, might have vital clinical and public health implications for community residents in China.

Third, our study is the first to indicate a stronger nonlinear negative relation of plasma selenium and first stroke in male participants with higher plasma vitamin E levels ( $\geq 13.5 \mu \mathrm{g} / \mathrm{mL})$ than those with lower plasma vitamin E levels $(<13.5 \mu \mathrm{g} / \mathrm{mL}$ ). This finding suggests that higher plasma selenium and higher plasma vitamin $\mathrm{E}$ levels may jointly decrease the first stroke risk. A previous meta-analysis demonstrated a significant inverse association between dietary vitamin $E$ intake and stroke risk, where a higher dietary vitamin E intake was associated with a lower risk of stroke [37]. The exact mechanisms underlying a high selenium $\times$ high vitamin $E$ interaction remain unclear. One plausible biological explanation for the interaction may be due to that both selenium and vitamin E belong to vital antioxidants and participate in protecting against brain oxidative stress [38], one of the hallmarks of stroke. Accordingly, high plasma vitamin E and selenium levels may share some cellular and molecular mechanisms for the pathogenesis of stroke, which could cause the interaction in the nonlinear negative relation of plasma selenium and first stroke in males. Further studies are warranted to verify this hypothesis.

While the mechanisms underlying the effect of selenium on first stroke remain inconclusive, an association seems reasonable due to several vital biological functions of selenium. Hosnedlova et al. [39] demonstrated that selenium mainly exerts a protective effect against oxidative lipid damage of the brain and modulates neurotoxicity and oxidative stress in the nervous tissue. Furthermore, modulation of 
inflammatory and metabolic signaling, as well as preservation of mitochondrial function may also be involved in the protective role of selenium on stroke [40,41]. Selenium deficiency in heart failure patients was independently associated with impaired exercise tolerance and a 50\% higher mortality rate, and impaired mitochondrial function in vitro, in human cardiomyocytes [42]. Ishrap et al. [43] reported that pharmacological selenium supplementation might have an unexpected ability to drive adaptive transcription to counter ferroptosis and protect neurons after stroke both in vitro and in vivo in animal models. Further studies are needed to illuminate the mechanisms underlying the association between plasma selenium and stroke.

Several possible limitations in this study should be mentioned. First, the plasma selenium concentrations only represent the baseline selenium levels of all participants; more frequent measurements during the follow-up would have strengthened the accuracy of our results. Second, only plasma selenium concentrations were used as the biomarker of selenium levels in our study; other biomarkers including whole blood and urinary selenium concentrations should also be considered when performing a sensitivity analysis to confirm our findings. Third, this was a nested, case-control study with a relatively small sample size from a community-based population and all stratified analyses were not prespecified, thus, this work was a product of hypothesis generating, and further larger-scale cohort studies are needed to verify the findings. Finally, since selenium is renally eliminated under the influence of diuretics, we adjusted all antihypertensive drugs together and did not analyze the effects of diuretic separately on the association, thus, further analysis is need to clarify this issue.

\section{Perspectives and significance}

In summary, we found a significantly nonlinear, inverse association between baseline plasma selenium and the risks of first stroke and first ischemic stroke in males, but not in females. In addition, no significant association between plasma selenium and first hemorrhagic stroke was found among either sex. If further confirmed, our findings may provide useful data for clinical and nutritional guidelines on the primary prevention of first stroke, by taking plasma selenium into account to serve as a potentially modifiable risk factor, and a possible biomarker for purposes of monitoring and intervention.

\section{Abbreviations}

CHHRS, China H-type Hypertension Registry Study; CDC, Chinese Centers for Disease Control and Prevention; $\mathrm{OR}$, odds ratio; $\mathrm{Cl}$, confidence intervals; $\mathrm{BMI}$, body mass index; SBP, systolic blood pressure; DBP, diastolic blood pressure; tHcy, total homocysteine; eGFR, estimated glomerular filtration rate; TC, total cholesterol; TG, triglycerides; HDL-C, high-density lipoprotein-cholesterol.

\section{Declarations}

Acknowledgements 
We acknowledge the contribution of all staff who participated in the present study as well as the study participants who shared their time with us.

\section{Authors' contributions}

Concept and design of this study: Dr. Ping Li and Xiping Xu; Manuscript composition: Dr. Huan Hu, and Ping Li; Data acquisition and collation: Lishun Liu; Statistical analysis: Huan Hu, Ping Wang and Ziyi Zhou; Reviewed and revised the manuscript: Ping Li, Xiao Huang, Huihui, Bao, and Xiping Xu. The other authors coordinated this analysis. All authors read and approved the final manuscript.

\section{Funding}

The study was supported by funding from the following: the National Key Research and Development Program [2016YFE0205400, 2018ZX09739010, 2018ZX09301034003], the Science and Technology Planning Project of Guangzhou, China [201707020010]; the Science, Technology and Innovation Committee of Shenzhen [GJHS20170314114526143, JSGG20180703155802047]; the Economic, Trade and Information Commission of Shenzhen Municipality [20170505161556110, 20170505160926390]; the National Natural Science Foundation of China [81960074, 81860058, 81500233, 81560079]; the Jiangxi Outstanding Person Foundation [20192BCBL23024], the Major Projects of the Science and Technology Department, Jiangxi [20171BAB205008, 20152ACB20022], the Funding Scheme for Academic and Technical Leaders of Major Disciplines, Jiangxi [20172BCB22027], and Special Funds for Guiding Local Scientific and Technological Development by the Central Government of China (S2019CXSFG0016).

\section{Conflict of Interest Disclosures:}

Dr. Xiping Xu reports grants from the National Key Research and Development Program [2016YFE0205400, 2018ZX09739010, 2018ZX09301034003), the Science and Technology Planning Project of Guangzhou, China (201707020010), the Science, Technology and Innovation Committee of Shenzhen [GJHS20170314114526143, JSGG20180703155802047), and the Economic, Trade and Information Commission of Shenzhen Municipality [20170505161556110, 20170505160926390].

Dr. Xiao Huang reports grants from the National Natural Science Foundation of China [81960074, 81500233], the Jiangxi Outstanding Person Foundation [20192BCBL23024], and Major projects of the Science and Technology Department, Jiangxi [20171BAB205008].

Dr. Ping Li reports grants from the National Natural Science Foundation of China [81560079, 81860058], Major Projects of the Science and Technology Department, Jiangxi, [20152ACB20022], Funding Scheme for Academic and Technical Leaders of Major Disciplines, Jiangxi [20172BCB22027], and Special Funds for Guiding Local Scientific and Technological Development by the Central Government of China (S2019CXSFG0016). No other disclosures were reported.

\section{Availability of data and materials}


All data are available from the corresponding author upon request.

\section{Ethics approval and consent to participate}

The protocol of the present study was approved by the the Ethics Committee of the Institute of Biomedicine, Anhui Medical University, Hefei, China. All participants signed an approved written consent form.

\section{Competing interests}

The authors declare that they have no competing interests.

\section{Author details}

${ }^{1}$ Department of Cardiovascular Medicine, the Second Affiliated Hospital of Nanchang University, No. 1 Minde Road, Nanchang, Jiangxi Province, China. ${ }^{2}$ Center for Prevention and Treatment of Cardiovascular Diseases, the Second Affiliated Hospital of Nanchang University, Nanchang, No. 1 Minde Road, Nanchang, Jiangxi Province, China. ${ }^{3}$ People's Hospital of Rongcheng, No. 298 Chengshan Avenue, Rongcheng, Shandong Province, China. ${ }^{4}$ Beijing Advanced Innovation Center for Food Nutrition and Human Health, College of Food Science and Nutritional Engineering, China Agricultural University, No. 17 Tsinghua East Road, Beijing, China. ${ }^{5}$ Institute of Biomedicine, Anhui Medical University, No. 81 Meishan Road, Hefei, Anhui Province, China. ${ }^{6}$ Shenzhen Evergreen Medical Institute, No. 16 Gaoxin Middle 1 Road, Shenzhen, China. ${ }^{7}$ School of Public Health (Shenzhen), Sun Yat-Sen University, No. 135 Xingang West Road, Guangzhou, Guangdong Province, China. ${ }^{8} \mathrm{Health}$ and Family Planning Commission, No. 688 Qingshan East Road, Rongcheng, Shandong Province, China. ${ }^{9}$ Department of Cardiology, Peking University First Hospital, No. 8 Xishiku Street, Beijing, China. ${ }^{10}$ Department of Population, Family and Reproductive Health, Johns Hopkins University Bloomberg School of Public Health, 3400 N. Charles Street, Baltimore, MD, 21205, USA

\section{References}

1. Zhou M, Wang H, Zeng X, Yin P, Zhu J, Chen W, et al. Mortality, morbidity, and risk factors in China and its provinces, 1990-2017: a systematic analysis for the Global Burden of Disease Study Lancet. 2019; 394: 1145-1158.

2. Wang W, Jiang B, Sun $H$, Ru X, Sun D, Wang L, et al. Prevalence, Incidence, and Mortality of Stroke in China: Results from a Nationwide Population-Based Survey of 480687 Adults. Circulation. 2017; 135: 759-771.

3. Wu S, Wu B, Liu M, Chen Z, Wang W, Anderson CS, et al. Stroke in China: advances and challenges in epidemiology, prevention, and management. Lancet Neurol. 2019; 18: 394-405.

4. Lackland D.T, Roccella E.J, Deutsch A.F, Fornage M, George M.G, Howard G, et al. Factors influencing the decline in stroke mortality: a statement from the American Heart Association/American Stroke 
Association. Stroke. 2014; 45: 315-353.

5. Uesugi S, Ishihara J, Iso H, Sawada N, Takachi R, Inoue M, et al. Dietary intake of antioxidant vitamins and risk of stroke: the Japan Public Health Center-based Prospective Study. Eur J Clin Nutr. 2017; 71: 1179-1185.

6. Mohammadifard N, Humphries KH, Gotay C, Mena-Sánchez G, Salas-SalvadóJ, Esmaillzadeh. A, et al. Trace minerals intake: Risks and benefits for cardiovascular health. Crit Rev Food Sci Nutr. 2019; 59: 1334-1346.

7. Rayman M.P. Selenium and human health. Lancet. 2012; 379: 1256-1268.

8. Roman M, Jitaru P, Barbante C. Selenium biochemistry and its role for human health. Metallomics. 2014; 6: 25-54.

9. Zoidis E, Seremelis I, Kontopoulos N, Danezis GP. Selenium-Dependent Antioxidant Enzymes: Actions and Properties of Selenoproteins. Antioxidants (Basel). 2018; 7: 66.

10. Loscalzo J. Keshan disease, selenium deficiency, and the selenoproteome. N Engl J Med. 2014; 370: 1756-1760.

11. Fang LQ, Goeijenbier M, Zuo SQ, Wang LP, Liang S, Klein SL, et al. The association between hantavirus infection and selenium deficiency in mainland China. Viruses. 2015; 7: 333-351.

12. Wang XL, Yang TB, Wei J, Lei GH, Zeng C. Association between serum selenium level and type 2 diabetes mellitus: a non-linear dose-response meta-analysis of observational studies. Nutr J. 2016; 15: 48-56.

13. Xu ZC, Shao HF, Li S, Zheng C. Relationships between the selenium content in flue-cured tobacco leaves and the selenium content in soil in ENSHI, China tobacco-growing area. Pak J Bot. 2012; 44: 1563-1568.

14. Dinh QT, Cui Z, Huang J, Tran TAT, Wang D, Yang W, et al. Selenium distribution in the Chinese environment and its relationship with human health: A review. Environ Int. 2018; 112: 294-309.

15. Hu XF, Stranges S, Chan LHM. Circulating Selenium Concentration Is Inversely Associated With the Prevalence of Stroke: Results From the Canadian Health Measures Survey and the National Health and Nutrition Examination Survey. J Am Heart Assoc. 2019; 8: e012290.

16. Hu XF, Sharin T, Chan HM. Dietary and blood selenium are inversely associated with the prevalence of stroke among Inuit in Canada. Trace. Elem. Med. Biol. 2017; 44: 322-330.

17. Wen Y, Huang S, Zhang Y, Zhang H, Zhou L, Li D, et al. Associations of multiple plasma metals with the risk of ischemic stroke: A case-control study. Int. 2019; 125: 125-134.

18. Merrill PD, Ampah SB, He K, Rembert NJ, Brockman J, Kleindorfer D, et al. Association between trace elements in the environment and stroke risk: The reasons for geographic and racial differences in stroke (REGARDS) study. J Trace Elem Med Biol. 2017; 42: 45-49.

19. Virtamo J, Valkeila E, Alfthan G, Punsar S, Huttunen JK, Karvonen MJ. Serum selenium and the risk of coronary heart disease and stroke. Am J Epidemiol. 1985; 122: 276-282. 
20. Xiao Y, Yuan Y, Liu Y, Yu Y, Jia N, Zhou L, et al. Circulating Multiple Metals and Incident Stroke in Chinese Adults. Stroke. 2019; 50: 1661-1668.

21. Jenkins DJA, Spence JD, Giovannucci EL, Kim YI, Josse R, Vieth R, et al. Supplemental Vitamins and Minerals for CVD Prevention and Treatment. J Am Coll Cardiol. 2018; 71: 2570-2584.

22. Wilhelm M, Ewers U, Schulz C. Revised and new reference values for some trace elements in blood and urine for human biomonitoring in environmental medicine. Int J Hyg Environ Health. 2004; 207: 69-73.

23. Meschia JF, Bushnell C, Boden-Albala B, Braun LT, Bravata DM, Chaturvedi S, et al. Guidelines for the primary prevention of stroke: a statement for healthcare professionals from the American Heart Association/American Stroke Association. Stroke. 2014; 45: 3754-3832.

24. Bleys J, Navas-Acien A, Guallar E. Serum selenium levels and all-cause, cancer, and cardiovascular mortality among US adults. Arch Intern Med. 2008; 168: 404-410.

25. Wei WQ, Abnet CC, Qiao YL, Dawsey SM, Dong ZW, Sun XD, et al. Prospective study of serum selenium concentrations and esophageal and gastric cardia cancer, heart disease, stroke, and total death. Am J Clin Nutr. 2004; 79: 80-85.

26. Stranges S, Navas-Acien A, Rayman MP, Guallar E. Selenium status and cardiometabolic health: state of the evidence. Nutr Metab Cardiovasc Dis. 2010; 20: 754-760.

27. Khan SU, Khan MU, Riaz H, Valavoor S, Zhao D, Vaughan L, et al. Effects of Nutritional Supplements and Dietary Interventions on Cardiovascular Outcomes: An Umbrella Review and Evidence Map. Ann Intern Med. 2019; 171: 190-198.

28. Rees K, Hartley L, Day C, Flowers N, Clarke A, Stranges S. Selenium supplementation for the primary prevention of cardiovascular disease. Cochrane. Database Syst Rev. 2013; 31: CD009671.

29. Brown DG, Burk RF. Selenium retention in tissues and sperm of rats fed a Torula yeast diet. J Nutr. 1973; 103: 102-108.

30. G Hardy, I Hardy. Selenium: the Se-XY nutraceutical. Nutrition. 2004; 20: 590-593.

31. L.Hatfield, U.Schweizer, P.A.Tsuji. V.N.Gladyshev. L Schomburg. Sex-specific differences in biological effects and metabolism of selenium, in: D L Hatfifield, et al. 4th ed. Selenium - Its Molecular Biology and Role in Human Health, Springer, New York, NY, 2016. pp. 214-220.

32. Pitts MW, Kremer PM, Hashimoto AC, Torres DJ, Byrns CN, Williams CS, et al. Competition between the Brain and Testes under Selenium-Compromised Conditions: Insight into Sex Differences in Selenium Metabolism and Risk of Neurodevelopmental Disease. J Neurosci. 2015; 35: 15326-15338.

33. Wang Y, Zhao F, Rijntjes E, Wu L, Wu Q, Sui J, et al. Role of Selenium Intake for Risk and Development of Hyperthyroidism. J Clin Endocrinol Metab. 2019; 104: 568-580.

34. Dekkers OlafM, Horváth-Puhó Erzsébet, Cannegieter SuzanneC, Vandenbroucke JanP, Sørensen HenrikToft, Jørgensen JensOttoL. Acute cardiovascular events and all-cause mortality in patients with hyperthyroidism: a population-based cohort study. Eur J Endocrinol. 2017; 176: 1-9. 
35. Xia Y, Hill KE, Li P, Xu J, Zhou D, Motley AK, et al. Optimization of selenoprotein P and other plasma selenium biomarkers for the assessment of the selenium nutritional requirement: a placebocontrolled, double-blind study of selenomethionine supplementation in selenium-deficient Chinese subjects. Am J Clin Nutr. 2010; 92: 525-531.

36. Lutz Schomburg, Marju Orho-Melander, Joachim Struck, Andrea Bergmann, Olle Melander et al. Selenoprotein-P Deficiency Predicts Cardiovascular Disease and Death. Nutrients. 2019; 11: 1852.

37. Cheng P, Wang L, Ning S, Liu Z, Lin H, Chen S, et al. Vitamin E intake and risk of stroke: a metaanalysis. Br J Nutr. 2018; 120: 1181-1188.

38. Beytut E, Yilmaz S, Aksakal M, Polat S, et al. The possible protective effects of vitamin $E$ and selenium administration in oxidative stress caused by high doses of glucocorticoid administration in the brain of rats. J Trace Elem Med Biol. 2018; 45: 131-135.

39. Hosnedlova B, Kepinska M, Skalickova S, Fernandez C, Ruttkay-Nedecky B, Malevu TD, et al. A Summary of New Findings on the Biological Effects of Selenium in Selected Animal Species-A Critical Review. Int J Mol Sci. 2017; 18: 2209.

40. Amani H, Habibey R, Shokri F, Hajmiresmail SJ, Akhavan O, Mashaghi A, et al. Selenium nanoparticles for targeted stroke therapy through modulation of inflammatory and metabolic signaling. Sci Rep. 2019; 9: 6044.

41. Mehta SL, Kumari S, Mendelev N, Li PA. Selenium preserves mitochondrial function, stimulates mitochondrial biogenesis, and reduces infarct volume after focal cerebral ischemia. BMC Neurosci. 2012; $13: 79$.

42. Nils Bomer, Niels Grote Beverborg, Martijn FHoes, Koen WStreng, Mathilde Vermeer, Martin M Dokter, et al. Selenium and outcome in heart failure. Eur J Heart Fail. 2019;6.

43. Alim I, Caulfield JT, Chen Y, Swarup V, Geschwind DH, Ivanova E, et al. Selenium Drives a Transcriptional Adaptive Program to Block Ferroptosis and Treat Stroke. Cell. 2019; 177: 1262-1279.

\section{Tables}

Table 1 Baseline Characteristics of male and female participants. ${ }^{a}$ 


\begin{tabular}{|c|c|c|c|c|}
\hline Characteristics & Total & Male & Female & $P$ value \\
\hline $\mathrm{N}$ & $n=2510$ & $n=1242$ & $n=1268$ & \\
\hline Age, y & $70.75 \pm 8.06$ & $71.42 \pm 8.09$ & $70.10 \pm 7.98$ & $<0.001$ \\
\hline $\mathrm{BMI}, \mathrm{kg} / \mathrm{m}^{2}$ & $26.19 \pm 4.10$ & $25.34 \pm 3.57$ & $27.02 \pm 4.41$ & $<0.001$ \\
\hline Current smoking, n (\%) & $551(21.95)$ & $547(44.04)$ & $4(0.32)$ & $<0.001$ \\
\hline Current alcohol drinking, $\mathrm{n}(\%)$ & $612(24.38)$ & $599(48.23)$ & $13(1.03)$ & $<0.001$ \\
\hline Baseline SBP, mmHg & $153.25 \pm 23.09$ & $150.80 \pm 22.34$ & $155.66 \pm 23.56$ & $<0.001$ \\
\hline Baseline DBP, mmHg & $85.25 \pm 12.30$ & $86.20 \pm 12.50$ & $84.33 \pm 12.02$ & $<0.001$ \\
\hline Self-reported hypertension, $\mathrm{n}(\%)$ & $1312(52.27)$ & $553(44.52)$ & $759(59.86)$ & $<0.001$ \\
\hline Self-reported diabetes, n (\%) & $424(16.89)$ & $161(12.96)$ & $263(20.74)$ & $<0.001$ \\
\hline Self-reported hyperlipidemia, n (\%) & $264(10.52)$ & $108(8.70)$ & $156(12.30)$ & 0.003 \\
\hline Self-reported atrial fibrillation, $\mathrm{n}(\%)$ & $46(1.83)$ & $26(2.09)$ & $20(1.58)$ & 0.335 \\
\hline Hypertension, $\mathrm{n}(\%)^{\mathrm{b}}$ & $2016(80.32)$ & $940(75.68)$ & $1076(84.86)$ & $<0.001$ \\
\hline Labor intensity, n (\%) & & & & $<0.001$ \\
\hline Mild & $1885(75.10)$ & $887(71.42)$ & $998(78.71)$ & \\
\hline Moderate & $488(19.44)$ & $280(22.54)$ & $208(16.40)$ & \\
\hline Severe & $137(5.46)$ & $75(6.04)$ & $62(4.89)$ & \\
\hline \multicolumn{5}{|l|}{ Medication use, n (\%) } \\
\hline Antiplatelet drugs & $83(3.31)$ & 47 (3.78) & $36(2.84)$ & 0.186 \\
\hline Lipid-lowering drugs & $44(1.75)$ & $15(1.21)$ & $29(2.29)$ & 0.039 \\
\hline Glucose-lowering drugs & $301(11.99)$ & $112(9.02)$ & $189(14.91)$ & $<0.001$ \\
\hline Antihypertensive drugs & $1152(45.90)$ & $476(38.33)$ & $676(53.31)$ & $<0.001$ \\
\hline \multicolumn{5}{|l|}{ Laboratory results } \\
\hline $\mathrm{TC}, \mathrm{mmol} / \mathrm{L}$ & $5.85 \pm 1.20$ & $5.64 \pm 1.08$ & $6.05 \pm 1.29$ & $<0.001$ \\
\hline $\mathrm{TG}, \mathrm{mmol} / \mathrm{L}$ & $1.40 \pm 0.85$ & $1.21 \pm 0.74$ & $1.59 \pm 0.91$ & $<0.001$ \\
\hline $\mathrm{HDL}-\mathrm{C}, \mathrm{mmol} / \mathrm{L}$ & $1.63 \pm 0.39$ & $1.63 \pm 0.42$ & $1.62 \pm 0.36$ & 0.558 \\
\hline Glucose, $\mathrm{mmol} / \mathrm{L}$ & $6.26 \pm 2.32$ & $6.09 \pm 2.09$ & $6.43 \pm 2.51$ & $<0.001$ \\
\hline tHcy, $\mu \mathrm{mol} / \mathrm{L}$ & $13.87 \pm 7.15$ & $15.26 \pm 8.58$ & $12.50 \pm 5.03$ & $<0.001$ \\
\hline eGFR, mL/min/1.73 $\mathrm{m}^{2}$ & $92.49 \pm 14.41$ & $92.26 \pm 15.06$ & $92.71 \pm 13.75$ & 0.428 \\
\hline
\end{tabular}




\begin{tabular}{|lllll} 
Vitamin $\mathrm{E}, \mathrm{\mu g} / \mathrm{mL}$ & $14.04 \pm 3.98$ & $12.90 \pm 3.27$ & $15.16 \pm 4.28$ & $<0.001$ \\
\hline Selenium, $\mathrm{ng} / \mathrm{mL}$ & $87.24 \pm 18.57$ & $87.68 \pm 18.58$ & $86.80 \pm 18.55$ & 0.230
\end{tabular}

a Variables are presented as mean \pm SD or $\mathrm{n}(\%) .{ }^{\mathrm{b}}$ Hypertension was defined as self-reported history of hypertension, or use of antihypertensive drugs, or SBP $\geq 140 \mathrm{~mm} \mathrm{Hg}$, or DBP $\geq 90 \mathrm{~mm} \mathrm{Hg}$. Abbreviations: BMI, body mass index; SBP, systolic blood pressure; DBP, diastolic blood pressure; TC, total cholesterol; TG, triglycerides; HDL-C, high-density lipoprotein-cholesterol; tHcy, total homocysteine; and eGFR, estimated glomerular filtration rate.

Table 2 Baseline Characteristics of cases and control participants. ${ }^{a}$ 


\begin{tabular}{|c|c|c|c|}
\hline Characteristics & First stroke cases & Non-stroke controls & $P$ value \\
\hline $\mathrm{N}$ & $n=1255$ & $n=1255$ & \\
\hline Age, y & $70.75 \pm 8.07$ & $70.76 \pm 8.06$ & 0.987 \\
\hline Male, n (\%) & $621(49.48)$ & $621(49.48)$ & 1.000 \\
\hline $\mathrm{BMI}, \mathrm{kg} / \mathrm{m}^{2}$ & $26.51 \pm 4.42$ & $25.87 \pm 3.73$ & $<0.001$ \\
\hline Current smoking, n (\%) & $296(23.59)$ & $255(20.32)$ & 0.048 \\
\hline Current alcohol drinking, n (\%) & $295(23.51)$ & $317(25.26)$ & 0.306 \\
\hline Baseline SBP, mmHg & $157.17 \pm 23.81$ & $149.34 \pm 21.66$ & $<0.001$ \\
\hline Baseline DBP, mmHg & $87.20 \pm 12.82$ & $83.31 \pm 11.43$ & $<0.001$ \\
\hline Self-reported hypertension, $\mathrm{n}(\%)$ & $746(59.44)$ & $566(45.10)$ & $<0.001$ \\
\hline Self-reported diabetes, n (\%) & $261(20.80)$ & $163(12.99)$ & $<0.001$ \\
\hline Self-reported hyperlipidemia, n (\%) & $129(10.28)$ & $135(10.76)$ & 0.696 \\
\hline Self-reported atrial fibrillation, n (\%) & $29(2.31)$ & $17(1.35)$ & 0.074 \\
\hline Hypertension, $\mathrm{n}(\%)^{\mathrm{b}}$ & $1075(85.66)$ & $941(74.98)$ & $<0.001$ \\
\hline Labor intensity, n (\%) & & & 0.003 \\
\hline Mild & $978(77.93)$ & $907(72.27)$ & \\
\hline Moderate & $221(17.61)$ & $267(21.27)$ & \\
\hline Severe & $56(4.46)$ & $81(6.45)$ & \\
\hline \multicolumn{4}{|l|}{ Medication use, n (\%) } \\
\hline Antiplatelet drugs & $60(4.78)$ & $23(1.83)$ & $<0.001$ \\
\hline Lipid-lowering drugs & $22(1.75)$ & $22(1.75)$ & 1.000 \\
\hline Glucose-lowering drugs & $193(15.38)$ & $108(8.61)$ & $<0.001$ \\
\hline Antihypertensive drugs & $664(52.91)$ & $488(38.88)$ & $<0.001$ \\
\hline \multicolumn{4}{|l|}{ Laboratory results } \\
\hline $\mathrm{TC}, \mathrm{mmol} / \mathrm{L}$ & $5.84 \pm 1.21$ & $5.85 \pm 1.20$ & 0.768 \\
\hline $\mathrm{TG}, \mathrm{mmol} / \mathrm{L}$ & $1.49 \pm 0.92$ & $1.31 \pm 0.77$ & $<0.001$ \\
\hline $\mathrm{HDL}-\mathrm{C}, \mathrm{mmol} / \mathrm{L}$ & $1.59 \pm 0.38$ & $1.66 \pm 0.40$ & $<0.001$ \\
\hline Glucose, $\mathrm{mmol} / \mathrm{L}$ & $6.54 \pm 2.53$ & $5.98 \pm 2.05$ & $<0.001$ \\
\hline tHcy, $\mu \mathrm{mol} / \mathrm{L}$ & $14.26 \pm 7.95$ & $13.47 \pm 6.22$ & 0.006 \\
\hline
\end{tabular}




\begin{tabular}{|llll|}
\hline eGFR, $\mathrm{mL} / \mathrm{min} / 1.73 \mathrm{~m}^{2}$ & $91.69 \pm 15.31$ & $93.29 \pm 13.40$ & 0.005 \\
\hline Vitamin $\mathrm{E}, \mu \mathrm{g} / \mathrm{mL}$ & $14.13 \pm 4.00$ & $13.95 \pm 3.95$ & 0.269 \\
\hline Selenium, $\mathrm{ng} / \mathrm{mL}$ & $86.63 \pm 17.63$ & $87.84 \pm 19.45$ & 0.101 \\
\hline
\end{tabular}

a Variables are presented as mean \pm SD or $\mathrm{n}(\%) .{ }^{\mathrm{b}}$ Hypertension was defined as self-reported history of hypertension, or use of antihypertensive drugs, or SBP $\geq 140 \mathrm{~mm} \mathrm{Hg}$, or DBP $\geq 90 \mathrm{~mm} \mathrm{Hg}$. Abbreviations: $\mathrm{BMI}$, body mass index; SBP, systolic blood pressure; DBP, diastolic blood pressure; TC, total cholesterol; TG, triglycerides; HDL-C, high-density lipoprotein-cholesterol; tHcy, total homocysteine; and eGFR, estimated glomerular filtration rate.

Table 3 Risk of first stroke (total and subtypes) associated with plasma selenium concentrations in total participants. ${ }^{a}$ 


\begin{tabular}{|c|c|c|c|c|c|}
\hline \multirow[t]{2}{*}{ Selenium, ng/mL } & \multirow[t]{2}{*}{ Cases/controls } & \multicolumn{2}{|l|}{ Model 1} & \multicolumn{2}{|l|}{ Model 2} \\
\hline & & OR $(95 \% \mathrm{Cl})$ & $P$ value & OR $(95 \% \mathrm{Cl})$ & $P$ value \\
\hline \multicolumn{6}{|l|}{ First total stroke } \\
\hline \multicolumn{6}{|l|}{ Tertiles } \\
\hline $\mathrm{T} 1(<79.1)$ & $420 / 417$ & Ref. & & Ref. & \\
\hline T2 $(79.1$ to $<94.1)$ & $434 / 402$ & $1.07(0.88,1.30)$ & 0.516 & $1.02(0.82,1.26)$ & 0.891 \\
\hline T3 $(\geq 94.1)$ & $401 / 436$ & $0.90(0.73,1.11)$ & 0.317 & $0.77(0.61,0.97)$ & 0.027 \\
\hline \multicolumn{6}{|l|}{ Categories } \\
\hline T1-T2 (<94.1) & $854 / 819$ & Ref. & & Ref. & \\
\hline T3 $(\geq 94.1)$ & $401 / 436$ & $0.87(0.73,1.04)$ & 0.119 & $0.76(0.63,0.93)$ & 0.007 \\
\hline \multicolumn{6}{|l|}{ Ischemic stroke } \\
\hline \multicolumn{6}{|l|}{ Tertiles } \\
\hline T1 $(<79.1)$ & $360 / 363$ & Ref. & & Ref. & \\
\hline T2 (79.1 to <94.1) & $372 / 340$ & $1.10(0.89,1.35)$ & 0.376 & $1.05(0.83,1.33)$ & 0.672 \\
\hline T3 ( $\geq 94.1)$ & $347 / 376$ & $0.92(0.74,1.14)$ & 0.444 & $0.78(0.60,0.99)$ & 0.045 \\
\hline \multicolumn{6}{|l|}{ Categories } \\
\hline T1-T2 (<94.1) & 732/703 & Ref. & & Ref. & \\
\hline T3 $(\geq 94.1)$ & $347 / 376$ & $0.87(0.72,1.06)$ & 0.163 & $0.75(0.61,0.93)$ & 0.009 \\
\hline \multicolumn{6}{|l|}{ Hemorrhagic stroke } \\
\hline \multicolumn{6}{|l|}{ Tertiles } \\
\hline T1 $(<79.1)$ & $58 / 54$ & Ref. & & Ref. & \\
\hline T2 (79.1 to <94.1) & $60 / 61$ & $0.88(0.50,1.57)$ & 0.673 & $0.76(0.38,1.55)$ & 0.455 \\
\hline T3 ( $\geq 94.1)$ & $53 / 56$ & $0.85(0.47,1.54)$ & 0.587 & $0.72(0.35,1.48)$ & 0.371 \\
\hline \multicolumn{6}{|l|}{ Categories } \\
\hline T1-T2 (<94.1) & $118 / 115$ & Ref. & & Ref. & \\
\hline T3 $(\geq 94.1)$ & $53 / 56$ & $0.92(0.57,1.47)$ & 0.718 & $0.85(0.48,1.50)$ & 0.577 \\
\hline
\end{tabular}

${ }^{a}$ ORs of first stroke (total), first ischemic and hemorrhagic stroke in relation to plasma selenium (tertiles) were analyzed using conditional logistic regression models. Model 1 is conditioned on the matching factors of age and sex; Model 2 is conditioned on the matching factors of age and sex, as well as 
adjusted for BMI, baseline SBP, baseline DBP, smoking status, alcohol consumption, labor intensity, baseline total homocysteine, vitamin $\mathrm{E}$, fasting glucose, estimated glomerular filtration rate (eGFR), antiplatelet drugs, lipoprotein-lowering drugs, glucose-lowering drugs, antihypertensive drugs, selfreported hypertension, self-reported atrial fibrillation, self-reported diabetes, and self-reported hyperlipidemia.

Table 4. The association of plasma selenium with risk of first stroke (total and subtypes) by sex. ${ }^{a}$ 


\begin{tabular}{lll}
\multicolumn{2}{c}{ bale participants } & \\
\hline Cases/controls & Model 1 & Model 2 \\
\cline { 2 - 3 } & $\begin{array}{ll}\text { OR }(95 \% \mathrm{Cl}) \\
P \text { value }\end{array}$ & $\begin{array}{l}\text { OR }(95 \% \mathrm{Cl}) \\
P \text { value }\end{array}$
\end{tabular}

Female participants

\begin{tabular}{lll} 
Cases/controls & Model 1 & Model 2 \\
\cline { 2 - 3 } & OR & OR \\
$(95 \% \mathrm{Cl})$ & $(95 \% \mathrm{Cl})$ \\
Pvalue & $\stackrel{P}{P \text { value }}$
\end{tabular}

\section{First total stroke}

Selenium Tertiles

\begin{tabular}{|c|c|c|c|c|c|c|}
\hline $\begin{array}{l}\mathrm{T} 1(<79.1 \\
\mathrm{ng} / \mathrm{mL})\end{array}$ & $206 / 193$ & Ref. & Ref. & $214 / 224$ & Ref. & Ref. \\
\hline $\begin{array}{l}\text { T2 }(79.1 \\
\text { to }<94.1)\end{array}$ & 218/183 & $\begin{array}{l}1.12(0.84 \\
1.49) 0.452\end{array}$ & $\begin{array}{l}1.11(0.80 \\
1.54) 0.519\end{array}$ & $216 / 219$ & $\begin{array}{l}1.04 \\
(0.80, \\
1.36) \\
0.764\end{array}$ & $\begin{array}{l}0.88 \\
(0.65, \\
1.19) \\
0.408\end{array}$ \\
\hline $\begin{array}{l}\text { T3 } \\
(\geq 94.1)\end{array}$ & $197 / 245$ & $\begin{array}{l}0.73(0.55 \\
0.98) 0.034\end{array}$ & $\begin{array}{l}0.67(0.48 \\
0.93) 0.017\end{array}$ & 204/191 & $\begin{array}{l}1.14 \\
(0.85, \\
1.54) \\
0.380\end{array}$ & $\begin{array}{l}0.85 \\
(0.61, \\
1.19) \\
0.353\end{array}$ \\
\hline \multicolumn{7}{|c|}{ Selenium Categories } \\
\hline $\begin{array}{l}\text { T1-T2 } \\
(<94.1)\end{array}$ & $424 / 376$ & Ref. & Ref. & $430 / 443$ & Ref. & Ref. \\
\hline $\begin{array}{l}\text { T3 } \\
(\geq 94.1)\end{array}$ & $197 / 245$ & $\begin{array}{l}0.69(0.54 \\
0.89) 0.003\end{array}$ & $\begin{array}{l}0.63(0.48 \\
0.83) 0.001\end{array}$ & 204/191 & $\begin{array}{l}1.12 \\
(0.86 \\
1.44) \\
0.399\end{array}$ & $\begin{array}{l}0.92 \\
(0.69 \\
1.22) \\
0.563\end{array}$ \\
\hline
\end{tabular}

\section{First ischemic stroke}

Selenium Tertiles

\begin{tabular}{|c|c|c|c|c|c|c|}
\hline $\begin{array}{l}\mathrm{T} 1(<79.1 \\
\mathrm{ng} / \mathrm{mL})\end{array}$ & $179 / 171$ & Ref. & Ref. & $181 / 192$ & Ref. & Ref. \\
\hline $\begin{array}{l}\text { T2 }(79.1 \\
\text { to }<94.1)\end{array}$ & $191 / 157$ & $\begin{array}{l}1.16(0.85 \\
1.57) 0.343\end{array}$ & $\begin{array}{l}1.17(0.82, \\
1.66) 0.387\end{array}$ & $181 / 183$ & $\begin{array}{l}1.05 \\
(0.79 \\
1.40)^{\prime} \\
0.716\end{array}$ & $\begin{array}{l}0.90 \\
(0.64, \\
1.25) \\
0.514\end{array}$ \\
\hline $\begin{array}{l}\text { T3 } \\
(\geq 94.1)\end{array}$ & $168 / 210$ & $\begin{array}{l}0.74(0.55 \\
1.01) 0.058\end{array}$ & $\begin{array}{l}0.67(0.47 \\
0.95) 0.027\end{array}$ & $179 / 166$ & $\begin{array}{l}1.17 \\
(0.85, \\
1.60) \\
0.330\end{array}$ & $\begin{array}{l}0.84 \\
(0.58, \\
1.21)^{\prime} \\
0.347\end{array}$ \\
\hline \multicolumn{7}{|c|}{ Selenium Categories } \\
\hline $\begin{array}{l}\text { T1-T2 } \\
(<94.1)\end{array}$ & $370 / 328$ & Ref. & Ref. & $362 / 375$ & Ref. & Ref. \\
\hline T3 & $168 / 210$ & 0.69 (0.53, & $0.61(0.45$ & $179 / 166$ & 1.14 & 0.89 \\
\hline
\end{tabular}




\begin{tabular}{|c|c|c|c|c|c|c|}
\hline \multicolumn{2}{|l|}{$(\geq 94.1)$} & $0.90) 0.006$ & \multicolumn{2}{|l|}{$0.83) 0.001$} & $\begin{array}{l}(0.86, \\
1.50) \\
0.362\end{array}$ & $\begin{array}{l}(0.65, \\
1.22) \\
0.479\end{array}$ \\
\hline \multicolumn{7}{|c|}{ First hemorrhagic stroke } \\
\hline \multicolumn{7}{|c|}{ Selenium Tertiles } \\
\hline $\begin{array}{l}\mathrm{T} 1(<79.1 \\
\mathrm{ng} / \mathrm{mL})\end{array}$ & $26 / 22$ & Ref. & Ref. & $32 / 32$ & Ref. & Ref. \\
\hline $\begin{array}{l}\text { T2 }(79.1 \\
\text { to }<94.1)\end{array}$ & $26 / 26$ & $\begin{array}{l}0.81(0.33 \\
2.00) 0.646\end{array}$ & $\begin{array}{l}0.88(0.25 \\
3.04) 0.840\end{array}$ & $34 / 35$ & $\begin{array}{l}0.98 \\
(0.46, \\
2.12) \\
0.962\end{array}$ & $\begin{array}{l}0.48 \\
(0.17 \\
1.37)^{\prime} \\
0.172\end{array}$ \\
\hline $\begin{array}{l}\text { T3 } \\
(\geq 94.1)\end{array}$ & $29 / 33$ & $\begin{array}{l}0.72(0.32 \\
1.60) 0.420\end{array}$ & $\begin{array}{l}0.80(0.25 \\
2.58) 0.714\end{array}$ & $24 / 23$ & $\begin{array}{l}1.05 \\
(0.43, \\
2.57) \\
0.919\end{array}$ & $\begin{array}{l}0.58 \\
(0.17 \\
1.92) \\
0.368\end{array}$ \\
\hline \multicolumn{7}{|c|}{ Selenium Categories } \\
\hline $\begin{array}{l}\text { T1-T2 } \\
(<94.1)\end{array}$ & $52 / 48$ & Ref. & Ref. & $66 / 67$ & Ref. & Ref. \\
\hline $\begin{array}{l}\text { T3 } \\
(\geq 94.1)\end{array}$ & $29 / 33$ & $\begin{array}{l}0.80(0.41 \\
1.54) 0.506\end{array}$ & $\begin{array}{l}0.86(0.33 \\
2.26) 0.761\end{array}$ & $24 / 23$ & $\begin{array}{l}1.06 \\
(0.54, \\
2.10) \\
0.862\end{array}$ & $\begin{array}{l}0.95 \\
(0.36, \\
2.46) \\
0.910\end{array}$ \\
\hline
\end{tabular}

${ }^{\text {a Model }} 1$ is conditioned on the matching factors of age and sex; Model 2 is conditioned on the matching factors of age and sex, as well as adjusted for BMI, baseline SBP, baseline DBP, smoking status, alcohol consumption, labor intensity, baseline total homocysteine, vitamin $\mathrm{E}$, fasting glucose, estimated glomerular filtration rate (eGFR), antiplatelet drugs, lipoprotein-lowering drugs, glucose-lowering drugs, antihypertensive drugs, self-reported hypertension, self-reported diabetes, self-reported atrial fibrillation, and self-reported hyperlipidemia. ${ }^{b}$ Adjusted $P$-interaction between sex and plasma selenium (T3, $\geq 94.1$ $\mathrm{ng} / \mathrm{mL} v s . \mathrm{T} 1-2,<94.1 \mathrm{ng} / \mathrm{mL}$ ) on first total stroke=0.029. Abbreviations: $\mathrm{T}$, tertile; OR,odds ratio; $\mathrm{Cl}$, confidence interval.

Table 5 Stratified analysis of the association between plasma selenium concentrations $(T 3, \geq 94.1 \mathrm{ng} / \mathrm{mL}$ vs. T1-2, $<94.1 \mathrm{ng} / \mathrm{mL}$ ) and incident risk of first total stroke in males. 


\begin{tabular}{|c|c|c|c|c|}
\hline \multirow[t]{2}{*}{ Subgroups } & \multicolumn{2}{|c|}{ No. of cases / No. of controls } & \multirow{2}{*}{$\begin{array}{l}\text { aAdjusted } \\
\text { Model } \\
\text { OR }(95 \% \mathrm{Cl})\end{array}$} & \multirow{2}{*}{$\begin{array}{l}P \text { for } \\
\text { interaction }\end{array}$} \\
\hline & $\begin{array}{l}\text { Selenium } \geq 94.1 \\
\mathrm{ng} / \mathrm{mL}\end{array}$ & $\begin{array}{l}\text { Selenium<94.1 } \\
\mathrm{ng} / \mathrm{mL}\end{array}$ & & \\
\hline Age, y & & & & 0.288 \\
\hline$<70$ & $98 / 110$ & $173 / 161$ & $\begin{array}{l}0.73(0.50 \\
1.08)\end{array}$ & \\
\hline$\geq 70$ & $99 / 135$ & $251 / 215$ & $\begin{array}{l}0.54(0.38 \\
0.76)\end{array}$ & \\
\hline $\begin{array}{l}\text { Body mass index, } \\
\mathrm{kg} / \mathrm{m}^{2}\end{array}$ & & & & 0.067 \\
\hline$<24$ & $44 / 89$ & $151 / 152$ & $\begin{array}{l}0.39(0.24 \\
0.63)\end{array}$ & \\
\hline$\geq 24$ & $153 / 156$ & $273 / 224$ & $\begin{array}{l}0.75(0.55 \\
1.02)\end{array}$ & \\
\hline Current smoking & & & & 0.739 \\
\hline No & $95 / 136$ & $233 / 231$ & $\begin{array}{l}0.72(0.51 \\
1.01)\end{array}$ & \\
\hline Yes & $102 / 109$ & $191 / 145$ & $\begin{array}{l}0.54(0.36 \\
0.80)\end{array}$ & \\
\hline $\begin{array}{l}\text { Current alcohol } \\
\text { drinking }\end{array}$ & & & & 0.230 \\
\hline No & $98 / 106$ & $232 / 207$ & $\begin{array}{l}0.74(0.51 \\
1.06)\end{array}$ & \\
\hline Yes & $99 / 139$ & $192 / 169$ & $\begin{array}{l}0.53(0.37 \\
0.77)\end{array}$ & \\
\hline SBP, mmHg & & & & 0.759 \\
\hline$<140$ & $46 / 92$ & $124 / 156$ & $\begin{array}{l}0.60(0.38 \\
0.96)\end{array}$ & \\
\hline$\geq 140$ & $151 / 153$ & $300 / 220$ & $\begin{array}{l}0.64(0.47 \\
0.88)\end{array}$ & \\
\hline Glucose, $\mathrm{mmol} / \mathrm{L}$ & & & & 0.898 \\
\hline$<6.1$ & $108 / 168$ & $274 / 284$ & $\begin{array}{l}0.66(0.48 \\
0.90)\end{array}$ & \\
\hline$\geq 6.1$ or diabetes $^{b}$ & $89 / 77$ & $150 / 92$ & $\begin{array}{l}0.66(0.42 \\
1.02)\end{array}$ & \\
\hline $\mathrm{TC}, \mathrm{mmol} / \mathrm{L}$ & & & & 0.402 \\
\hline
\end{tabular}




\begin{tabular}{|c|c|c|c|c|}
\hline$<5.78$ & 95/107 & $262 / 236$ & $\begin{array}{l}0.77(0.54, \\
1.10)\end{array}$ & \\
\hline$\geq 5.78$ & $102 / 138$ & $162 / 140$ & $\begin{array}{l}0.53(0.36, \\
0.78)\end{array}$ & \\
\hline $\mathrm{TG}, \mathrm{mmol} / \mathrm{L}$ & & & & 0.611 \\
\hline$<1.17$ & $115 / 160$ & $246 / 255$ & $\begin{array}{l}0.71(0.52, \\
0.98)\end{array}$ & \\
\hline$\geq 1.17$ & $82 / 85$ & $178 / 121$ & $\begin{array}{l}0.55(0.36 \\
0.84)\end{array}$ & \\
\hline $\begin{array}{l}\text { eGFR, } \\
\mathrm{mL} / \mathrm{min} / 1.73 \mathrm{~m}^{2}\end{array}$ & & & & 0.753 \\
\hline$<90$ & $64 / 68$ & $173 / 141$ & $\begin{array}{l}0.71(0.45, \\
1.10)\end{array}$ & \\
\hline$\geq 90$ & 133/177 & $251 / 235$ & $\begin{array}{l}0.61(0.45 \\
0.83)\end{array}$ & \\
\hline tHcy, $\mu \mathrm{mol} / \mathrm{L}$ & & & & 0.117 \\
\hline$<12.5$ & $89 / 105$ & $129 / 142$ & $\begin{array}{l}0.81(0.54 \\
1.22)\end{array}$ & \\
\hline$\geq 12.5$ & $108 / 140$ & 293/234 & $\begin{array}{l}0.55(0.39 \\
0.76)\end{array}$ & \\
\hline Vitamin $E, \mu \mathrm{g} / \mathrm{mL}$ & & & & 0.007 \\
\hline$<13.5$ & $117 / 132$ & 270/277 & $\begin{array}{l}0.85(0.62, \\
1.17)\end{array}$ & \\
\hline$\geq 13.5$ & $80 / 113$ & $154 / 99$ & $\begin{array}{l}0.39(0.25 \\
0.60)\end{array}$ & \\
\hline
\end{tabular}

a ORs of first total stroke in relation to serum selenium levels were calculated using multivariate logistic regression models. Each subgroup analysis adjusted, if not stratified, for age, BMI, baseline SBP, baseline DBP, smoking status, alcohol consumption, labor intensity, baseline total homocysteine, vitamin $E$, fasting glucose, estimated glomerular filtration rate (eGFR), antiplatelet drugs, lipoprotein-lowering drugs, glucose-lowering drugs, antihypertensive drugs, self-reported hypertension, self-reported diabetes, selfreported atrial fibrillation, and self-reported hyperlipidemia. ${ }^{b}$ Diabetes was defined as self-reported history of diabetes mellitus, or use of anti-diabetic medications, or fasting glucose $\geq 7.0 \mathrm{mmol} / \mathrm{L}$. Abbreviations: $\mathrm{TC}$, total cholesterol; T, tertile; OR, odds ratio; $\mathrm{Cl}$, confidence interval.

\section{Figures}



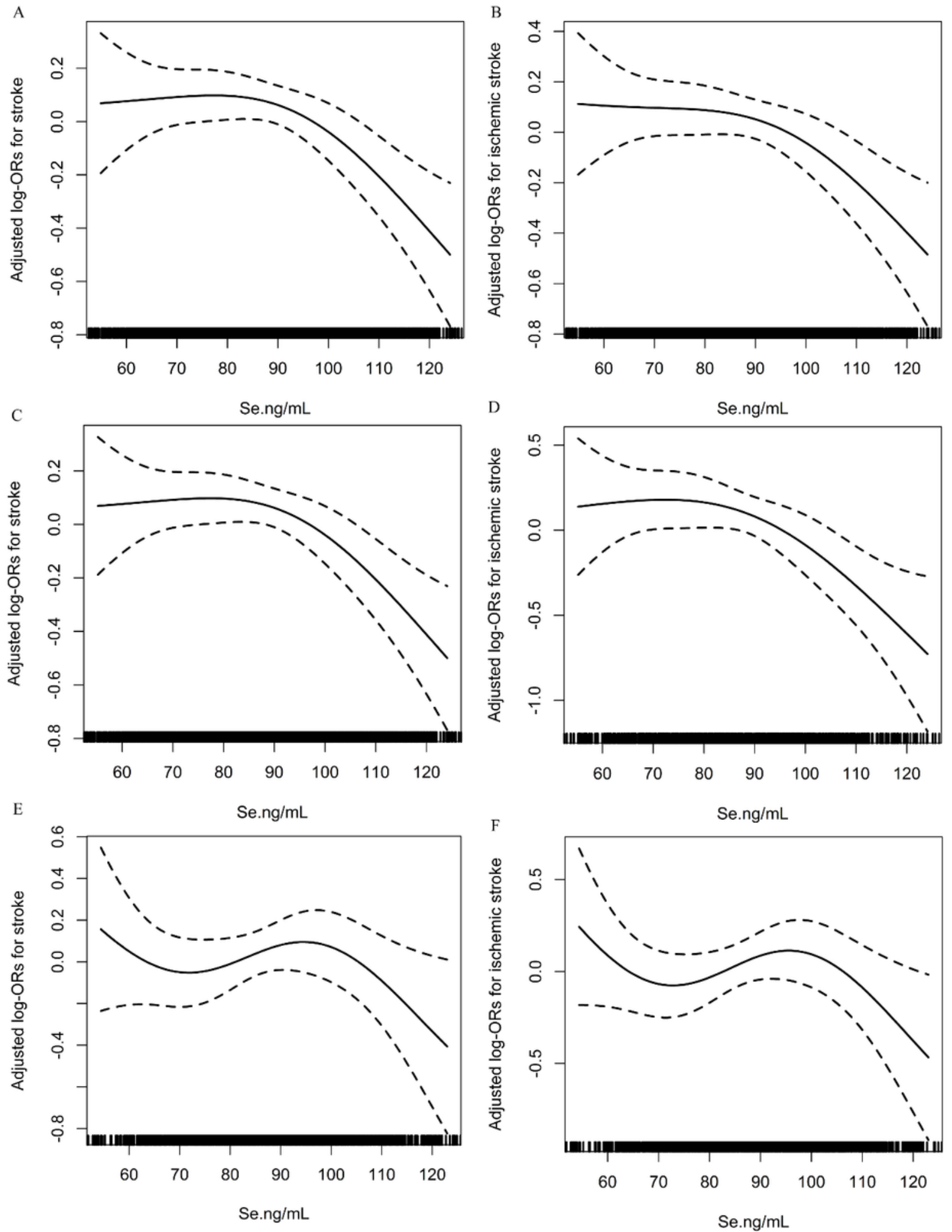

\section{Figure 1}

The association between baseline plasma selenium with the risk of first total stroke and first ischemic stroke. Odds ratios for first total stroke (A) total population, (C) males, (E) females, and for first ischemic stroke (B) total population, (D) males, (F) females by plasma selenium levels. In addition to the matching factors (age and sex), the splines also adjusted for BMI, baseline SBP, baseline DBP, smoking status, alcohol consumption, labor intensity, baseline total homocysteine, vitamin E, fasting glucose, estimated 
glomerular filtration rate (eGFR), antiplatelet drugs, lipoprotein-lowering drugs, glucose-lowering drugs, antihypertensive drugs, self-reported hypertension, self-reported diabetes, self-reported atrial fibrillation, and self-reported hyperlipidemia.

\section{Supplementary Files}

This is a list of supplementary files associated with this preprint. Click to download.

- Supplementalmaterials9.doc 